\title{
Etiology of renal failure and peritoneal dialysis complications in Isfahan
}

\author{
Soheila Mojdeh ${ }^{1}$, Shirin Karimi ${ }^{2}$, Ali Mehrabi ${ }^{2}$, Soheila Bakhtiari ${ }^{*}$ \\ ${ }^{1}$ Nursing and Midwifery School, Isfahan University of Medical Sciences, Isfahan, Iran; mojdeh@mail.mui.ac.ir \\ *Corresponding Author: bakhtiari@nm.mui.ac.ir \\ 2Al-Zahra Hospital Isfahan University of Medical Sciences, Isfahan, Iran; kshirinarad@gmail.com, mehrabi@mui.ac.ir
}

Received 24 August 2013; revised 24 September 2013; accepted 8 October 2013

Copyright (c) 2013 Soheila Mojdeh et al. This is an open access article distributed under the Creative Commons Attribution License, which permits unrestricted use, distribution, and reproduction in any medium, provided the original work is properly cited.

\section{ABSTRACT}

Introduction: Worldwide specific diseases are jeopardizing people's health in the world as well as in Iran. Chronic renal failure as a developed and irreversible failure is usually progressive. End Stage Renal Disease (ESRD) is a situation when renal function is not sufficient to preserve one's life leading to acute uremia resulting in dialysis and/or kidney transplantation for the patients. Although dialysis methods bring about complications for the patients, peritoneal dialysis is relatively cost-effective and more convenient to survive. The present study aimed to investigate (the) Etiologic factor of renal failure and imposed complications of peritoneal dialysis in the patients of Isfahan Alzahra hospital. Materials and Methods: It was a cross-sectional descriptive study conducted on 67 patients in Isfahan Peritoneal Dialysis Center. The data from the patients were collected through a two-section questionnaire whose first section was allocated to demographic information and the second part was related to the disease and complications of peritoneal dialysis. The collected data were analyzed by SPSS version 18. Results: The findings showed that there were $39(58 \%)$ males and $28(42 \%)$ females. Mean age of the subjects was 48 (18.8) years old. Regarding marital status, $65 \%$ were married and $35 \%$ were single. Considering complications, 28 subjects $(53.5 \%)$ had infectious complications while 24 subjects (46.2\%) had non-infectious complications. The highest frequency in etiologic factor of renal failure was diabetes mellitus in 29 subjects $(43.9 \%)$ and the lowest for polycystic kidney in 2 subjects (3\%); in addition, hypertension was observed in 51 subjects (77.3\%). Discussion: The most frequent and important complication of peritoneal dialysis catheters is infection, which may result in catheter loss and discontinuation of peritoneal dialysis (PD). Diabetes and hypertension were found as the most important etiologic factors for renal failure. They should also be considered as two major risk factors in prevention of renal diseases.

Keywords: Complications; Peritoneal Dialysis; Epidemiologic

\section{INTRODUCTION}

Worldwide specific diseases jeopardize people's health in the world as well as in Iran. Chronic renal failure as a developed and irreversible failure is usually progressive. End Stage Renal Disease (ESRD) is a situation wherein renal function is not sufficient to preserve one's life. At this stage, all the patients need dialysis or kidney transplantation [1]. According to Statistics Center of Iranian Specific Disease Association and Renal Patients Support Association, about 60,000 people die yearly of chronic renal failure [2]. The number of dialysis patients in Isfahan is 1500 people, and every year the number of the Patients on hemodialysis increases by $15 \%$ [3].

Peritoneal dialysis (PD) is one of the modes of renal replacement therapy being utilized for the management of end-stage renal failure worldwide, and it is a low-cost, convenient and efficient treatment by which a high number of the patients keep on living and experience longer life expectancy [1]. Since the incidence of hemodialysis and peritoneal dialysis increased, the number of incidents of the dialysis cases rose 3.3 percent in 2009, to 113,636; with 2759 patients receiving a pre-emptive transplant as their first ESRD modality, and 116,395 total patients 
began ESRD therapy in 2009. More than 106,000 dialysis patients started ESRD treatment on hemodialysis, and 7094 started on peritoneal dialysis [4]. About 5\% of the patients needing dialysis prefer peritoneal dialysis. Based on the latest statistics, at the present time, 24,000 detected patients are at ESRD. The number is predicted to increase to 40,000 in 2012 [5]. According to the report of the Management Center for Specific Diseases in the Ministry of Health and Medical Education, the population of patients with end-stage renal disease is 32,000 in Iran which seems to have increased to 40,000 by 2010 [6]. Since peritoneal dialysis burdens lower social cost, it is recommended for high risk patients with serious contraindications. Whereas peritoneal dialysis has complications, comparing to hemodiaysis, it has advantages as lower cost, patients' independency to the device, better control of BP, etc. Peritoneal Dialysis could help preventing the tree-times-a-week transfer of patients to hospital and could be advised in high-risk patients, but the procedure is not without complications. The lower the common side effects are, the better health care plans can be designed. The purpose of the current research was to define etiologic factors of renal failure and.

\section{MATERIALS AND METHODS}

It was a cross-sectional descriptive study conducted on 67 patients in Isfahan Peritoneal Dialysis Center The data were collected from the available patients files at nursing department of Dialysis Center through a two-section questionnaire whose first section was allocated to demographic information (first name, family name, questionnaire code, age, sex, height, marital status, occupation, education (educational level, residing location), and the second that was patients' disease data (accompanying diseases, addiction, cause of renal failure etc.).
Moreover, the data of Complications including 1) Infectious (Catheter exit site infection, Peritoneal internal infection) 2) Non-infectious (Abdominal hernia, Loose catheter, Catheter site leak, Dacron removal, Catheter removal and Replacement of catheter) was recorded.

\section{RESULT}

The findings showed that there were 39 male (58\%) and 28 female subjects (42\%). Mean age of the subjects was 48 (18.8) years old. Taking education, 27 (39.4\%) had primary school, 21 (31.8\%) middle school and high school and 5 (7.6\%) had university education. Sixty subjects (91\%) were living in urban areas and 6 (9\%) in rural areas.

Based on diagnosis and treatment profile of the patients reported by nephrologists, the highest frequency of etiologic factor of renal failure was diabetes in 29 subjects (43.9\%) and the lowest of polycystic kidney in 2 subjects (3\%) (Diagram 1).

Regarding accompanying diseases, 51 subjects (77.3\%) were hypertensive and 31 (47\%) were diabetic.

In the ongoing study, $68 \%$ of patients had complication. The highest frequency distribution of complications in peritoneal dialysis patients was infectious complicates 28 (53.5\%) and, non-infection complications complicates in 24 subjects (46.2\%). infection complications were Catheter exit site infection10 (19.23\%), Peritoneal internal infection 18 (34.62\%) and, Non-infectious complications including Abdominal hernia 2 (3.85\%), Loose catheter 8 (15.38\%), Catheter site leak 6 (11.54\%) Dacron removal 6 (11.54\%), (Table 1). According to the results of the present study, $77 \%$ of the patients rationally exchanged their dialysis connector tub of catheter each six months; $14 \%$ were due to infection of site and $4 \%$ due to rupture or having a side hole in (Table 2 ).

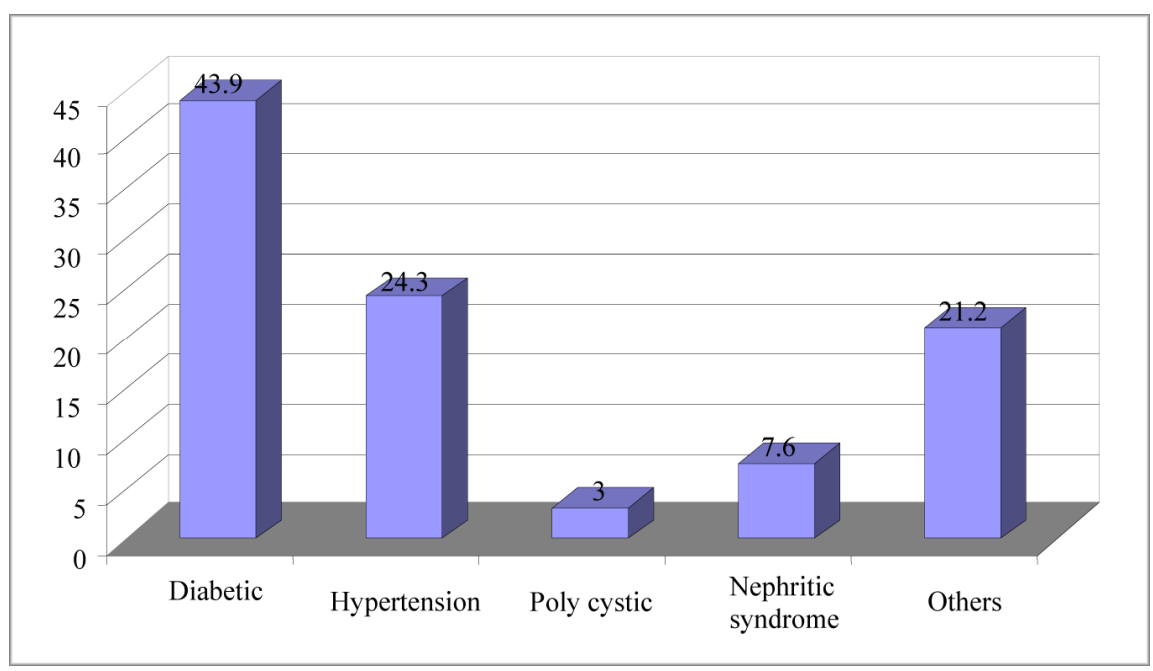

Diagram 1. Frequency distribution of renal failure in peritoneal dialysis patients. 
Table 1. Frequency distribution of complications in peritoneal dialysis patients.

\begin{tabular}{ccc}
\hline Complications & $\mathrm{N}$ & $\%$ \\
\hline Infectious & 28 & 53.5 \\
Catheter exit site infection & 10 & 19.23 \\
Peritoneal internal infection & 18 & 34.62 \\
Non-infectious & 24 & 46.2 \\
Abdominal hernia & 2 & 3.85 \\
Loose catheter & 8 & 15.38 \\
Catheter site leak & 6 & 11.54 \\
Dacron removal & 6 & 11.54 \\
Catheter removal & 2 & 3.85 \\
\hline
\end{tabular}

\section{DISCUSSION}

Considering The complications, the findings showed that $77 \%$ of the patients change their dialysis catheter each six months and only $14 \%$ were as a result of infection and $4 \%$ due to rapture or a side whole but, Rahimian et.al showed that $41.6 \%$ of the patients experienced peritonitis, $6.8 \%$ had catheter exit site infections and 9.3\% had inappropriate catheterization [7]. Of course, prevention of infection around catheter is one of the ways to prevent peritonitis. In our study $77 \%$ of patients had routinely exchanged connector tube of catheter and, 22\% had exchange dialysis Catheter causing replacement from whole place too. This can decrease the rate of peritonitis. The highest frequency was catheter site infection in addition to catheter removal from abdomen; the lowest was for accidental catheter removal (5.7\%). It should be noticed that peritonitis is one of the most important complications of peritoneal dialysis. One of the preventive strategies against peritonitis is to prevent the infection of catheter site as well as antibiotic therapy [8].

Catheter site leak is one of the most important noninfectious complications of peritoneal dialysis. Leakage of dialysate from catheter site tends to occur early after catheter placement, in association with high dialysate volumes, and in those with a weak abdominal wall (such as those with a history of multiple surgeries or pregnancies). In addition, leaks frequently occur only after a patient becomes physically active on a standard ambulatory peritoneal dialysis regimen, the reported incidence of per catheter leak is widely variable (1 to 40 percent) [9].

Results of the study carried out by Brendan showed common noninfectious complications of peritoneal dialysis such as perioperative Catheter complications (perforation of viscus or hemorrhage), obstruction to flow leakage, pain, Related to increased intra-abdominal pressure hernia, pleural leak (hydrothorax), Metabolic
Table 2. Frequency distribution Exchanged connector tube of catheter based on the reason.

\begin{tabular}{ccc}
\hline The reasons for the change & $\mathrm{N}$ & $\%$ \\
\hline Routine catheter exchange (each 6 months & 59 & 77 \\
Side hole or rupture & 4 & 5.8 \\
Infection & 13 & 17.2 \\
Total & 76 & 100 \\
\hline
\end{tabular}

(hyperglycemia hypertriglyceridemia) [10]. On the other hand, hernia as another non-infectious complication was observed in $14.3 \%$ of the cases. It was similar to the survey results by Saha which showed hernias, hydrothorax, hemoperitoneum, pancreatitis, ischemic colitis and necrotizing enterocolitis, pneumoperitoneum are common noninfectious complications [11]. Although peritoneal dialysis as a treatment for renal failure is greatly in demand, abdominal hernia is seen in this method; $30 \%$ of the patients have been reported by other various studies to develop hernia [12], which is more than what was reported in the present study.

Other result showed the highest frequency distribution of cases for renal failure was for diabetes (43.9\%) and the lowest for polycystic kidney. In another survey it was reported that the most common causes of CRF are hypertension (30.5\%) and diabetes mellitus (30.1\%) [13]. in the same way afshar reported The etiology of CRF in Iran included: diabetes mellitus in $26.8 \%$, hypertension in $13.5 \%$, obstructive uropathy in $12 \%$, cystic and congenital disorders in $10.3 \%$, glomerulonephritis in $6.5 \%$, urinary tract infections in $4 \%$, vasculitis in $2 \%$, tubulointerstitial nephritis and pregnancy related in $0.8 \%$ each and unknown causes in $29.5 \%$ of the patients [14]. In addition Portole's study showed etiology of ESRD in all patients by age, gender, race, is diabetics, hypertension, glomerulonephritis, cystic kidney [15]. In the present study, blood pressure and diabetes are the most common cause(s) of renal failure Known for mortality risk factors in the above mentioned study, regarding accompanying diseases, $77.3 \%$ and $47 \%$ of the patients were hypertensive and diabetic respectively. Today, over 25.8 million people in the US [16] and over 5\% of the population in Iran suffer from diabetes.

Hypertension is highly prevalent among diabetic patients, especially those of diabetic type II. Nowadays, more than half of diabetic patients suffer from hypertension. In fact, diabetes accompanied with hypertension doubles the complications and enhances the mortality risk among these patients [17]. More than two out of 1000 individuals suffer from chronic renal failure. Diabetes and hypertension have been known as two common reasons for chronic renal failure, which concords with the results of the present study [18]. 


\section{CONCLUSION}

The most frequent and important complication of peritoneal dialysis catheters is infection, which may result in catheter loss and discontinuation of peritoneal dialysis (PD) and the significant issue is that diabetes and hypertension have shown the highest prevalence as etiologic factors for renal failure and should be considered as two major risk factors of renal diseases in Iran.

\section{ACKNOWLEDGEMENTS}

We thank medical university of Isfahan for supported this study, and especial thanks from the Al-Zahra Educational medical Centre personal which help us in the investigation.

\section{REFERENCES}

[1] Alwakeel, J.S., Alsuwaida, A., Askar, A., Memon, N., Usama, S., Alghonaim, M., Feraz, N.A., Shah, I.H. and Wilson, H. (2011) Outcome and complications in peritoneal dialysis patients: A five-year single center experience. Saudi Journal of Kidney Diseases and Transplantation, 22, 245-251. http://www.ncbi.nlm.nih.gov/pubmed/21422621

[2] Namadi, M. and Movahedipour, A. (2009) Quality of life in patients after renal transplantation in comparison with intermittent hemodialysis. Journal of Ardabil University of Medical Sciences, 9, 171-179.

http://journals.arums.ac.ir/index.php/jarums/article/view/ 491

[3] Sodavy, M. (2013) In interview with mehr News Agency -IRNA. News Code: 1646353.

http://www.mehrnews.com/detail/News/1646353

[4] Bethesda (2011) Incidence, prevalence, patient characteristics, and treatment modalities. US Renal Data System, USRDS 2011 Annual Data Report: Atlas of Chronic Kidney Disease and End-Stage Renal Disease in the United States, National Institutes of Health, National Institute of Diabetes and Digestive and Kidney Diseases. http://www.usrds.org/2011/view/v2_01.asp

[5] Shahgholian, N., Ghafourifard, M. and Shafiei, F. (2011) The effect of sodium and ultra-filtration profile combination and cold dialysate on hypotension during Hemodialysis and its symptoms. Iranian Journal of Nursing and Midwifery Research, 16, 212-216.

[6] Shahgholian, N., Tajdari, S. and Nasiri, M. (2012) Reviewing and comparing self-concept in patients undergoing hemodialysis and peritoneal dialysis. Iranian Journal of Nursing and Midwifery Research, 17, S88-S94.

[7] Rahimian, M., Karimi, M., Hassan Lotfi, M., Nouri Majlan, N., Nourani, F.A. and Parande, K. (2008) Dialysis complications Peritoneal dialysis in Shahid Rahnemoun Yazd Hospital: Review of 10 years. Journal of Shaeed Sadoughi University, 16, 388. http://jssu.hbi.ir/browse.php?a_id=664\&sid=1\&slc_lang= fa
[8] Miles, R., Hawley, C.M., McDonald, S.P., Brown, F.G., Rosman, J.B., Wiggins, K.J., Bannister, K.M. and Johnson, D.W. (2009) Predictors and outcomes of fungal peritonitis in peritoneal dialysis patients. Kidney International, 76, 622-628.

http://espace.library.uq.edu.au/view/UQ:202691 http://dx.doi.org/10.1038/ki.2009.202

[9] Schmidt, R.J. and Holley, J.L. (2012) Noninfectious complications of peritoneal dialysis catheters. http://www.uptodate.com/contents/noninfectious-complic ations-of-peritoneal-dialysis-catheters

[10] McCormick, B.B. and Bargman, J.M. (2007) Noninfectious complications of peritoneal dialysis: Implications for patient and technique survival. Journal of the American Society of Nephrology, 18, 3023-3025. http://jasn.asnjournals.org/content/18/12/3023.full

[11] Saha, T.C. and Singh, H. (2007) Noninfectious complications of peritoneal dialysis. Southern Medical Journal, 100, 54-58.

http://www.ncbi.nlm.nih.gov/pubmed/17269526 http://dx.doi.org/10.1097/01.smj.0000253477.82103.a6

[12] Gianetta, E., Civalleri, D., Serventi, A., Floris, F., Mariani, F., Aloisi, F. and Saffioti, S. (2004) Anterior tension-free repair under local anesthesia of abdominal wall hernias in continuous ambulatory peritoneal dialysis patients. Hernia-The World Journal of Hernia and Abdominal Wall Surgery, 8, 354-357.

http://www.springerlink.com/content/eupcggeylc9k06h3/f ulltext.html

[13] Malekmakan, L., Haghpanah, S., Pakfetrat, M., Malekmakan, A., Khajehdehi, P. (2009) Causes of chronic renal failure among Iranian hemodialysis patients. Saudi Journal of Kidney Diseases and Transplantation, 20, 501-504.

[14] Afshar, R., Sanavi, S. and Salimi, J. (2007) Epidemiology of chronic renal failure in Iran: A four year single-center experience. Saudi Journal of Kidney Diseases and Transplantation, 18, 191-194. http://www.ncbi.nlm.nih.gov/pubmed/17496393

[15] Bethesda (2012) Atlas of chronic kidney disease and end-stage renal disease in the United States. National Institutes of Health, National Institute of Diabetes and Digestive and Kidney Diseases. US Renal Data System, USRDS 2012 Annual Data Report.

[16] CDC (2010) Diagnosed and undiagnosed diabetes in the United States, all ages, 2010. National Diabetes Fact Sheet. Center of Disease and Prevention. http://www.cdc.gov/diabetes/pubs/estimates11.htm

[17] Brimble, K.S., Walker, M., Margetts, P., Kundhal, K.K. and Rabbat, C.G. (2006) Meta-analysis: Peritoneal membrane transport, mortality, and technique failure in peritoneal dialysis. Journal of the American Society of $\mathrm{Ne}$ phrology, 17, 2591-2598. http://dx.doi.org/10.1681/ASN.2006030194

[18] Buren, P.N.V. and Toto, R. (2012) Hypertension in diabetic nephropathy: Epidemiology, mechanisms, and management. Advances in Chronic Kidney Disease, 18, 28-41. http://www.ncbi.nlm.nih.gov/pmc/articles/PMC3221014/ 